\title{
(Re)inventando futuros possíveis: Design crítico e especulativo
}

\author{
(Re)inventing possible futures: Speculative and critical design
}

\author{
BARROS, Camila Bezerra Furtado; Doutora; Universidade Federal do Ceará \\ camilabfb@gmail.com.br \\ MACHADO, Lara Maria de Araújo; Graduanda; Universidade Federal do Ceará \\ laramachadoam@gmail.com
}

\section{Resumo}

O presente artigo se propõe a apresentar a prática projetual: design crítico e especulativo, apresentando sua conceituação e exemplificando. Para tanto, retomamos a etimologia da palavra design, a partir de Flusser (2007) e trouxemos, com Bruno Latour (2014), a defesa de que design pode substituir a palavra "revolução". Em diálogo com Krippendorff (2000), Forty (2007), Ferrara (2002) e Souza Leite (1996), apresentamos o designer como construtor de discursos. Ao que tange o design crítico e especulativo, trouxemos o conceito de Dunne e Raby (2013) e exemplificamos com projetos nacionais e internacionais. Introduzimos esse posicionamento projetual contextualizando no design conceitual e finalizamos propondo um quadro resumo que o caracteriza.

Palavras Chave: Design Crítico e Especulativo; Design Conceitual; Discurso; Crítica.

\begin{abstract}
This paper intends to present the projectual practice: speculative and critical design, showcasing its conception and exemplifying it. For such, it returns to the etymology of the word design, from Flusser (2007) and it carries, with Bruno Latour (2014), who defends the idea that design could replace the word 'revolution'. Dialoguing with Krippendorff (2000), Forty (2007), Ferrara (2002) and Sousa Leite (1996), it presents, the designer as a discourse creator. When it comes to speculative and critical design, it introduces the topic by placing conceptual design into context and bringing the concept of Dunne and Raby (2013) and exemplifying it with local and international projects. It ends proposing an overview which characterizes this projectual practice.
\end{abstract}

Keywords: speculative and critical design; conceptual design; discourse; criticism. 


\section{Design como antídoto}

Flusser (2007), em seu capítulo Construções, no livro Mundo codificado, debate sobre a etimologia da palavra design. $O$ autor passeia pelos significados correlatos ao caráter substantivo e verbal do termo de origem inglesa. Flusser pontua que os significados estão associados à "astúcia" e "fraude" e vai questionar como para a palavra design foram atribuídos significados amplamente difundidos internacionalmente, em detrimento de outros. O filósofo argumenta que essa é uma questão a ser debatida pelo viés da linguagem, pois trata-se de uma análise semântica.

Tecendo a discussão sobre o termo, Flusser coloca que em certa concepção "a palavra design ocorre em um contexto de astúcias e fraudes, o designer é, portanto, um conspirador malicioso que se dedica a engendrar armadilhas" (idem, p. 182). Ainda nesse sentido, o autor apresenta que outros termos estão associados à palavra design, entre eles: mecânica e técnica. Mecânica, de origem grega mechos, designa um mecanismo que objetiva enganar e, assim, a máquina seria, portanto, um dispositivo de enganação, armação que dribla a natureza, que engana por meio da técnica.

Prolongando a discussão sobre o termo, Flusser apresenta a designação de técnica, do grego thecné, que significa arte. No latim, o termo equivalente a thecné é ars, que traz a noção de "manobra", já artfex (artista) significaria "impostor" e dessa raiz vêm as palavras artifício e artificial. Flusser traz também a objeção de Platão à arte e à técnica, como sendo um processo impostor, que faz o homem contemplar ideias deformadas. Após o Renascimento, os espaços da arte e da técnica foram divididos em campos distintos do saber e do fazer, essa separação começou a ser questionável no final do séc. XIX. Com efeito, a palavra design faria ponte entre esses campos, na brecha, por exprimir um lugar entre técnica e arte, o que, segundo o autor, torna possível uma nova forma de cultura (idem, p. 184).

\footnotetext{
“(...) o que une os termos mencionados é fato de que todos apresentam conotações de, entre outras coisas, engodo e malícia. A cultura para qual o design poderá melhor preparar o caminho será aquela consciente de sua astúcia. A pergunta é: A quem e ao que enganamos quando nos inscrevemos na cultura (na técnica e na arte, em suma, no design?) (...) Em suma: o design que está por trás de toda cultura consiste em, com astúcia, nos transformar de simples mamíferos condicionados pela natureza em artistas livres" (idem, p. 184).
}

Flusser demonstra preocupação com uma desvalorização do design, que contra a natureza, agindo para a artificialidade, é "naturalizado" em um mundo que vive a cultura do projeto. E tornando-se consciente que toda cultura é trapaça, compreendemos que a artificialidade promovida pelo design seria autoengano. Ele observa, sabiamente, que isso se dá a um certo tipo de design que se faz na oposição técnica versus mundo natural. Um outro caminho argumentativo que podemos tomar, ele atenta, está no design associado "a signo (Zeichen), indício (Anzeichen), presságio (Vorzeichen), insígnia (Abzeichen) e nesse caso poderia surgir uma explicação distinta, mas igualmente plausível para a situação atual da palavra" (idem, p. 186).

A expansão do sentido do design é entendida por Bruno Latour (2014), em Prometeu Cauteloso, como indício da forma como lidamos com os objetos, com nossas ações e, propriamente, com a noção de modernidade (que segundo o autor, nunca a alcançamos). Ele nos fala sobre "questões de fato", referentes à objetividade da matéria e "questões de interesse", 
contemplando ao que se refere ao humano, de caráter subjetivo. Nos provoca no sentido de que quanto mais os objetos se tornam "questão de interesse", mais eles se enquadram no que seria objeto de design.

Se é verdade que a atual situação histórica é definida por uma completa desconexão entre duas grandes narrativas alternativas - uma baseada na emancipação, no desapego, na modernização, no progresso e no controle; e outra, completamente diferente, baseada no apego, na precaução, no envolvimento, na dependência e no cuidado -, então a pequena palavra "design" pode servir como um importante medidor para nos ajudar a detectar o rumo que tomamos e o quão bem tem se saído o modernismo (e também o pósmodernismo). Para colocar a questão de maneira mais provocativa, eu diria que design é um dos termos que substituiu a palavra "revolução"! (Latour, 2014, p.04).

O designer, portanto, deve ser aquele que reelabora, que recria - não o criar ex nihilo, mas que interfere na realidade, e, assim, a (re)modifica. Essa é, portanto, uma atividade política, estando os designers atentos ou não. Latour nos diz que fazer design "é o antídoto para os atos de fundar, colonizar, estabelecer ou romper com o passado. É o antídoto para a arrogância e para a busca de certezas absolutas, começos absolutos e de desvios radicais" (idem, p.8). 0 design se funda na realidade.

\section{O discurso do designer: Articulando futuros possíveis}

O ser humano, além de ser natural, mamífero, é ser social. O design inscrito na cultura, na economia e na sociedade é, em consciência ou não, também discursivo ${ }^{1}$. Nessa perspectiva, artistas livres, que, com astúcia, enganam a natureza, atuam com seus dispositivos no jogo de articulações simbólicas nas construções discursivas e, assim, também podem produzir uma "artificialidade" no campo da linguagem, promovendo ressignificações a produtos projetuais para além de sua funcionalidade objetiva. O produto-objeto (entendemos aqui o termo objeto em uma visão expandida, cabendo qualquer produto projetual seja ele tridimensional ou não) é, portanto, simbólico, de enfoque subjetivo e imerso em uma conjuntura a qual dialoga.

Ao tratamos da produção de discurso, é necessário passarmos pela dimensão da linguagem, que comumente é discutido sob a ótica das produções verbais. Entretanto, a linguagem também é expressa sem palavras, conforme ressalta Ferrara (2002) ao afirmar que códigos auditivos, táteis, visuais são expressões de linguagem. Para compreensão de um discurso em sua totalidade, é preciso abranger a elasticidade da linguagem em seus amplos mecanismos de expressão, relacionando o sintático e o semântico, para, então, perceber as entrelinhas dos textos, o campo simbólico de articulação de significados para a produção dos discursos. Souza Leite (1996), no artigo Discurso do design gráfico como polifonia, traz de maneira lúcida essa noção

\footnotetext{
${ }^{1}$ Tomamos a noção de discurso dos pós-estruturalistas Laclau e Mouffe que definem o discurso enquanto prática social de caráter político. O discurso, para os autores, em sua rede de articulações simbólicas é capaz de estabelecer, manter e/ou transformar as relações de poder (LACLAU; MOUFFE, 2004).
} 
expandida do design quando o coloca o designer não como fazedor de coisas, mas como construtor de discurso, de linguagem sincrônica, conjugados em signos que concorrem na mesma situação temporal e espacial.

$\mathrm{Na}$ esteira histórica do século $\mathrm{XX}$, as mercadorias passaram a ser concebidas como objetos de consumo simbólico e o designer passou a projetar o intangível. Entretanto, ultrapassando o intangível como argumento passional ao consumo, o designer, enquanto ator social, poderia (e ainda pode) atuar na concepção de produtos reflexivos, com ou sem apelo comercial. Forty (2007), em Objetos de Desejo, identifica que o design é uma atividade expressiva nas formações ideológicas. $O$ autor nos alerta que designers costumam não perceber a dimensão de alcance de sua atividade, tornando esta, certamente, uma questão importante a constar na formação em design: a relação design e sociedade. Conforme coloca Necyk e Ferreira (2010): "Essa relação demanda uma abordagem epistemológica na qual o campo de ação do design vai para além da confecção de objetos sob uma perspectiva funcionalista" (NECYK E FERREIRA, 2010, p. 02).

Nessa discussão, Klaus Krippendorff (2000), em seu texto Design Centrado no Ser humano: Uma Necessidade Cultural, cita Philip Agree para defender que a tecnologia evoluiu ao ponto de tornar a atividade projetual um modo de vida. Ele coloca: "A noção modernista de uma cultura baseada na ciência cedeu lugar para uma cultura em que a atividade projetual não é mais um privilégio, pois já penetrou em quase todas as áreas da vida social" (KRIPPENDORFF, 2000, p.92). Esse argumento retoma o discutido por Flusser (2007) que a cultura projetual está arraigada em nosso modo de vida e isso, contribui para uma banalização do design. Sob esse olhar, o design é posto em xeque e, em resposta aos anseios desse homem que o questiona, tem sua práxis expandida para além do modelo do designer "criador" de coisas. Flusser provoca, então, que o designer deve continuamente reprojetar o seu fazer e o seu discurso, para que o design sobreviva como profissão:

\begin{abstract}
A educação deveria refletir mais a respeito do estado do design e inquirir sobre as práticas linguísticas dos designers, em vista do papel que eles precisam desempenhar dentro do próprio mundo que pretendem mudar. (...) A pesquisa científica é, no fim das contas, a busca contínua de dados no passado, disponíveis no presente, a fim de extrair generalizações para o futuro. Os designers, ao contrário, buscam possibilidades de alterar determinismos históricos, de inventar futuros e fazer com que sejam possíveis (idem, p. 93 e 94. Grifo nosso).
\end{abstract}

O autor coloca que a maior desafio do ensino de design está na promoção de estudos que investiguem formas de narrar futuros imagináveis. Argumenta que para que o designer (comparando a poetas e escritores) possa projetar esses futuros. Ele deve, para tanto, aprender a articular futuros possíveis através da sua própria linguagem, e isso, acreditamos, é fruto da prática discursiva que emerge do fazer. O que Krippendorff propõe com essa discussão é o fortalecimento do discurso do design, enquanto prática social para reflexão e promoção de futuros possíveis.

\title{
3 Design Crítico e Especulativo
}

O pesquisador brasileiro Carlo Franzato (2011) em seu texto O Processo de criação no design conceitual: Explorando o potencial reflexivo e dialético do projeto, apresenta o design 
conceitual como a ação projetual que busca a promoção da reflexão e a expressão de ideias. Assim como Krippendorff, o autor faz uma comparação à produção verbal da literatura em particular da poesia, argumentando que no design conceitual há o protagonismo da ideia. Os designers exploram as potencialidades reflexivas e dialéticas do processo de criação do design, abrindo espaço para pensar e discutir os assuntos mais diversos.

Entretanto, o autor apresenta estes objetos como "autotélicos", ou seja, que não possuem nenhuma finalidade para mais de si mesmo. Mas qual seria essa finalidade no objeto conceitual? A funcionalidade estaria somente relacionada ao campo do fazer? O objeto conceitual sofre um deslocamento em seu status de objeto funcional, seu objetivo está em uma nova função, que, como dito, emana do simbólico, advém da linguagem.

Sem dúvida, a linguagem é nossa forma de coordenação mais importante. Nós criamos e coordenamos o mundo perceptível enquanto falamos uns com os outros. Construímos tecnologia através de conversações. O design não pode ser bem-sucedido sem a comunicação entre designers e com os usuários. Por essa razão: Coordenações adquirem significado social através de narrativas e diálogos. Artefatos são materializados através da linguagem (KRIPPENDORFF, 2000, p. 90).

Retomando a discussão, segundo Krippendorff (2000), em seu texto Design Centrado no Ser Humano: Uma Necessidade Cultural, o design passou por uma trajetória de paradigmas, partindo do foco em produtos, seguindo para bens, informação e, identidades, interfaces, rede de multiusuários, planejamentos e discursos. Essa trajetória demonstraria um aumento gradual no sentido de uma "cultura projetual" que julga seus produtos como práticas sociais e que considera cada vez mais aspectos sociais no ato projetual (KRIPPENDORFF, 2000).

O design conceitual não é uma nova área do design, como design de produtos, é, porém, um posicionamento transversal às diversas especializações (FRANZATO, 2012). Designs conceituais não são assim chamados porque não foram realizados, mas sim porque celebram a não-realidade, sua importância está em serem feitos de ideias (DUNNE; RABY, 2013). O design conceitual celebra esse fato, fazendo uso de sua 'imaterialidade' para ganhar dinamismo e liberdade projetual. Os objetos finais podem ser abstratos, celebrando o processo e não fazendo esforço de atingir um realismo. O design conceitual se mostra, assim, como um espaço paralelo para especulação que usa objetos hipotéticos ou fictícios para exploração de ideias.

Ao expandir o universo da prática do design, a discussão para diferenciar a arte do design emerge, principalmente, do design conceitual. Segundo Franzato (2012, p.227): "O design conceitual está para o design como a arte conceitual está para a arte". No contexto dessa pesquisa, vale identificar um pensamento da arte contaminado pelo design e vice e versa, como se dá no momento contemporâneo. Fica evidente que uma separação nítida entre arte e design já não é mais interessante, visto que ambas as áreas se engajam hoje na transformação social para pensar futuros e rever passados.

Como visto em Krippendorf (2000), uma das grandes metas do estudo em design seria investigar formas de narrar futuros imagináveis, articulando futuros por meio da sua linguagem e reforçando a prática social do design para reflexão. Em resposta a essas necessidades, surge o design crítico e especulativo com um olhar específico voltado para a noção de futuros e como resultado das necessidades de projeto mais complexas presentes no contemporâneo. 
O design crítico e especulativo é um termo cunhado por Anthony Dunne e Fiona Raby, por volta dos anos 90, sendo, inicialmente, denominado design crítico. Definir design crítico e especulativo se mostra uma tarefa complexa, pois esse posicionamento é contaminado pela arte e ainda recebe diversos nomes, sendo chamado de também critical design, design futures, design fiction, entre outros.

O design crítico e especulativo normalmente utiliza elementos que provocam familiaridade com nosso cotidiano e com as tecnologias emergentes, a fim de gerar impacto e discussões. A motivação do posicionamento projetual especulativo surge a partir do cotidiano e visa uma própria extrapolação criativa ao projetar realidades futuras alternativas. Ao especular sobre a nossa realidade, passamos a compreendê-la melhor, tornando-a maleável e passível de análise e experimentação em nosso próprio cotidiano (DUNNE e RABY, 2013).

Essa abordagem projetual tem linhas de encontro com cinema, poesia, literatura, psicologia entre outros. Segundo Krippendorf: “(...) a diferença entre escritores de ficção e designers é que as fiç̧ões dos designers devem ser realizáveis, devem introduzir mudanças em nossos mundos" (KRIPPENDORFF, 2000, p.93). Dessa forma, propostas de design crítico e especulativo geralmente promovem esse cenário de projeção de um futuro que não é tão distante de nós a ponto de gerar um futuro totalmente não-ancorado no presente. Direciona-se ao futuro para promover a reflexão de questões do presente.

\section{Figura 1 - Cone of probable futures (2006)}

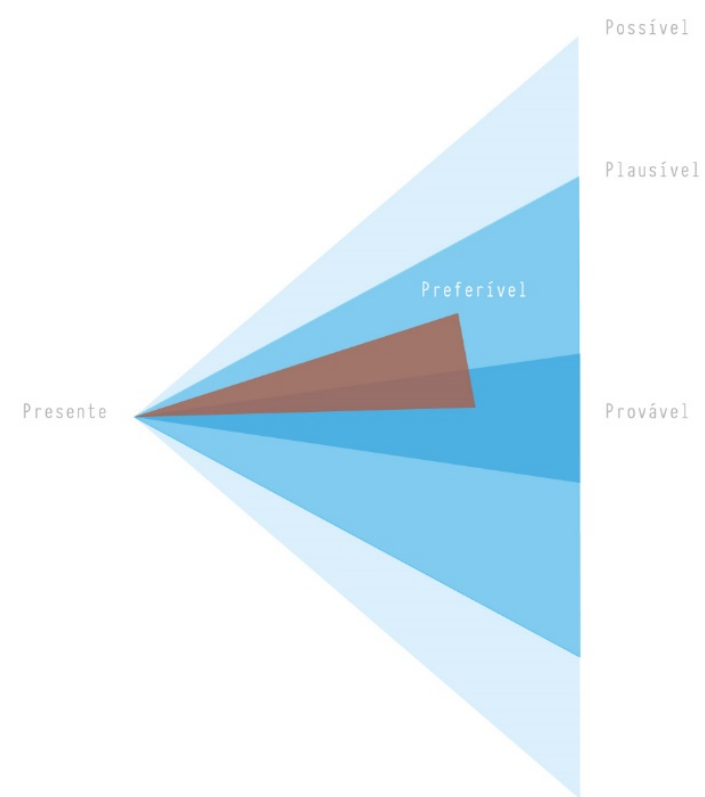

Fonte: Speculative Everything (2013).

Segundo Dunne e Raby (2013), em seu livro Speculative Everything, o potencial especulativo nasce do presente, ocupando o espaço do preferível, dentro do espaço maior do que é possível, do que é plausível e do que é provável que o futuro de fato seja (Figura 1). A demonstração do distópico permite a reflexão sobre futuros a evitar, quando os designers 
especulativos expõem futuros não-desejáveis, suscitando, assim, uma reflexão e, esperançosamente, uma mudança na sociedade. A busca de cenários tende a uma radicalização do presente e de tendências do presente, isso permite uma reflexão sobre ele e sobre nossos caminhos como sociedade.

Como exemplo de uma iniciativa especulativa, o projeto Afterlife de James Auger e Jimmy Loizeau toca diretamente em um ponto delicado a respeito da morte humana. O conceito principal do projeto consiste na utilização de uma célula de combustível microbiana no processo de decomposição do corpo, o que transforma o cadáver em uma bateria e armazena a energia vital, transformando-a em energia potencial para equipamentos elétricos.

Figura 2 - Afterlife, Auger-Loizeau. Caixão com célula de combustível microbiana (2008).

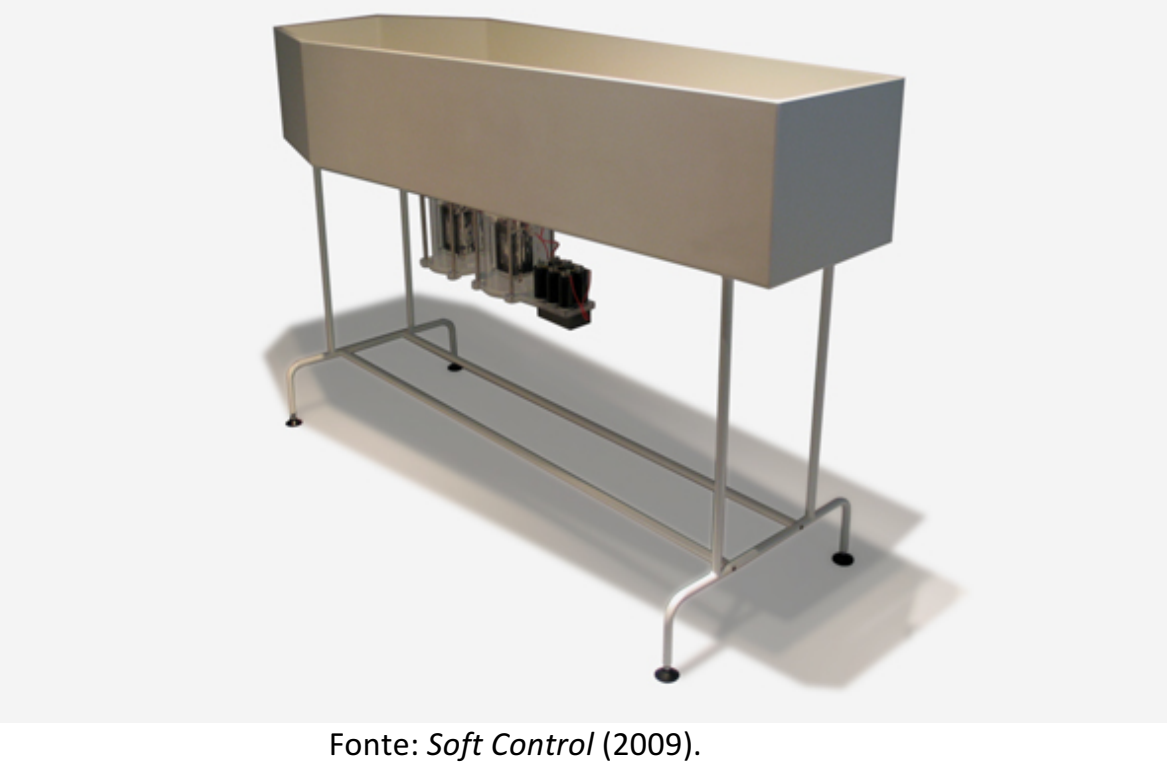

O projeto polemiza ao tocar em um assunto delicado como a morte e tratá-lo de maneira prática, como sendo uma transferência energética, onde o cadáver ainda pode ser utilizado pelas pessoas vivas. O projeto quer propor um diálogo metafísico, o qual examina a mudança cultural de sistemas de crenças religiosas e avança para algo mais factual, baseado na ciência (AUGER, 2013). Aqui a tecnologia age para promover metaforicamente uma espécie de 'prova de vida após a morte', a vida transformando-se em energia na bateria. Além disso, podemos ainda analisar a questão como uma reflexão sobre a necessidade energética da nossa sociedade e as fontes de geração de energia disponíveis, trazendo, também, a discussão ao tocante da sustentabilidade.

No âmbito brasileiro, o design crítico e especulativo ainda é um campo incipiente, o qual é pouco discutido e trabalhado, deixando clara, assim, a importância da discussão realizada neste trabalho. Dentro de breves iniciativas nacionais presentes nesse posicionamento, temos o estúdio A Parede que, apesar de situado em Berlim, é formado pelos brasileiros Pedro Oliveira e Luiza Prado. O próprio estúdio se define como um hub para projetos em andamento e se propõe a usar o design como um método de 'alfabetização política' e questionar a responsabilidade de práticas materiais em assegurar e perpetuar problemas como colonialismo, problemas relacionados ao 
gênero, entre outros. Eles também alegam querer, por meio do design, 'usar e abusar' de ferramentas do design para assegurar futuros não-hegemônicos e não-colonialistas.

Um projeto da dupla que ainda está em andamento é o Design in Times of Crisis (2016), no qual eles se propõem a explorar como a pesquisa em design ajuda a nos preparar para um estado de exceção. O foco é uma realidade distópica de um país em desenvolvimento que permite explorar as relações entre política, economia e caos social e desenvolvimentos tecnológicos. Eles estão coletando relatos vividos pelos familiares e amigos dos pesquisadores, distopias da vida comum e cotidiana no Brasil.

Figura 3 - Design in times of crisis (2016).

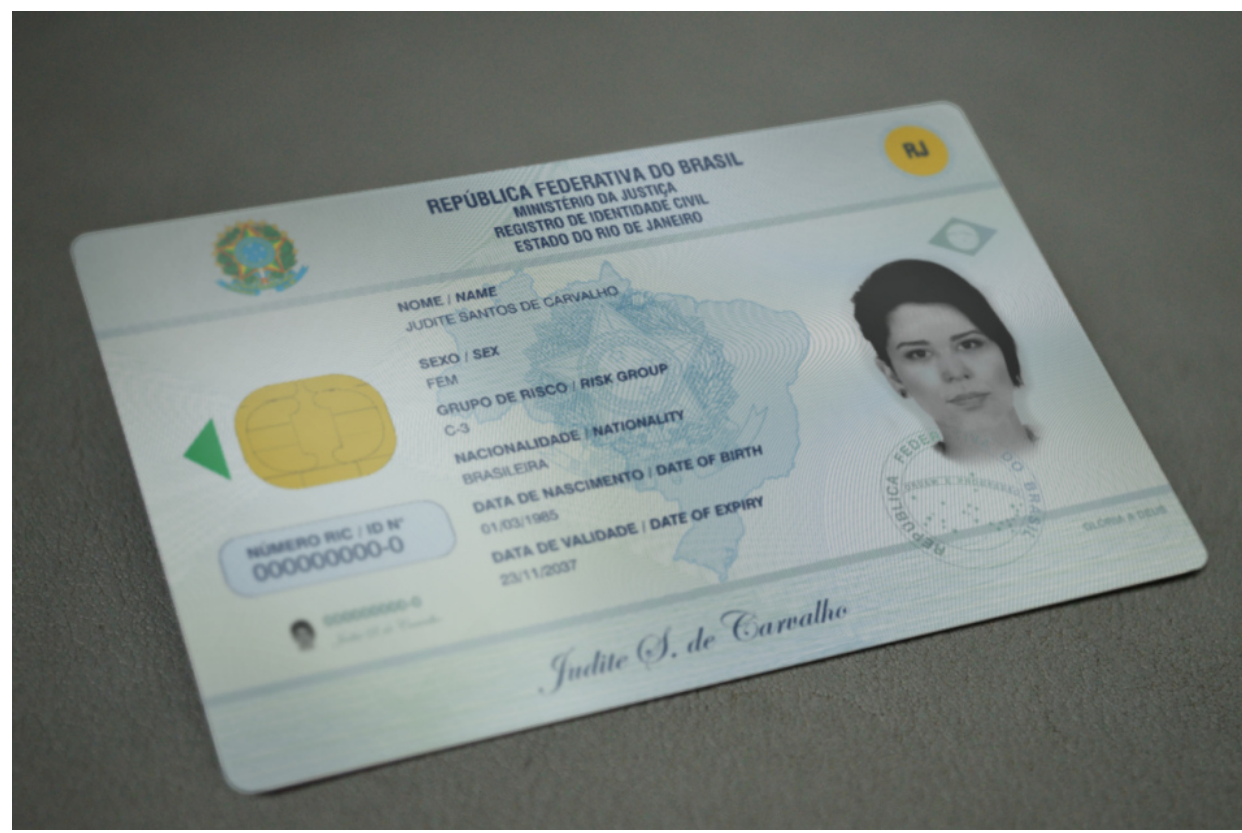

Fonte: A Parede (2016)

\section{Conclusão}

No presente trabalho, defendemos a importância de compreender o design, para além da materialidade, entendendo que o design dos objetos nasce dos fatos de interesse. Para tanto, é importante perceber que o fazer do designer se constitui em um fazer simbólico e, de maneira atenta ou não, é na construção de discursos presentificados nos produtos projetuais que esse sujeito se coloca no mundo. Ao explorar brevemente o design conceitual, buscamos entender a conjuntura que o estabeleceu no campo do design e como chegamos as abordagens contemporâneas no fazer do design.

O design é percebido como uma ponte entre a técnica e a arte, sendo a discussão para diferenciar design e arte cada vez menos relevante sob a ótica do contemporâneo. Diante do debate proposto sobre design conceitual, funcionalidade, arte, criação de discursos e papel social do designer, apresentamos o design crítico e especulativo com um posicionamento transdisciplinar que surge a partir das necessidades do sujeito contemporâneo, que o produz e/ou o consome. 
São resumidas abaixo, para efeito conclusivo, algumas das principais características dos processos do design crítico e especulativo:

- Posicionamento transdisciplinar que tem como base o cotidiano e as tecnologias atuais/emergentes; o designer cria cenários de futuros possíveis para produtos e sistemas.

- Criação de cenários de futuro não apartados do presente, de modo a gerar identificação no espectador.

- Esse posicionamento se propõe a levantar um debate, fazer surgir um olhar ou discurso crítico em torno de uma questão e analisar os tipos de futuro desejados ou não.

- Relevância da autoria e subjetividade do designer.

- Designer como produtor de discursos, mais do que materialidade, apresentando objetivos não diretamente mercadológicos.

- O projeto como um processo experimental de reflexão, especialmente sobre o presente em que vivemos.

- Ferramenta provocativa e crítica, muitas vezes por meio da ironia e/ou sátira.

- Aproximação e troca de conhecimentos com outras áreas como cinema, literatura, psicologia, sociologia, dentre outras.

Mais que conceituar o design crítico e especulativo como prática projetual ancorada ao design conceitual, algo que por si já justificaria a escrita de tal artigo, consideramos que é importante explicitar que essa prática evidencia o caráter social do fazer do designer, colocando-o como sujeito de sua produção, que não se resume a sua atuação em um contexto mercadológico (que por vezes exige "neutralidade"). Enquanto sujeito comunicante, o produto do trabalho do designer declara, simbolicamente, o seu estar no mundo, promovendo valores (culturais, políticos, ideológicos...), provocando reflexões e podendo transformar, ou seja, o design comunica e constrói discursos. Não alcançando a esperada transformação radical moderna, mas sim reformulações do cotidiano a partir do design, o design tem esse potencial transformador. Cabe a nós, designers, percebermos que, ultrapassando a perspectiva instrumental do projeto, temos uma força "revolucionária" em cada objeto pensado, projetado e propagado.

\section{Referências}

A PAREDE. Design in Times of Crisis. 2016. Disponível em: <http://a-pare.de/2016/design-intimes-of-crisis/> Acesso em 2 abr. 2018.

AUGER, James. Speculative design: crafting the speculation. Digital Creativity. v. 24, n. 1, p. 11-35, 2013. Disponível em:

<http://www.tandfonline.com/doi/full/10.1080/14626268.2013.767276?scroll=top\&needAccess= true>. Acesso em: 1 abr. 2018. 
DUNNE, Anthony; RABY, Fiona. Speculative Everything: design, fiction and social dreaming. Cambridge: MIT Press, 2013

FERRARA, Lucrécia. Leitura sem palavras. São Paulo: Ática, 2002.

FLUSSER, Vilém. O mundo codificado: por uma filosofia do design e da comunicação. São Paulo: Cosac Naify, 2007.

FORTY, Adrian. Objeto do desejo: design e sociedade desde 1750. São Paulo. Cosac Naify, 2007.

FRANZATO, Carlo. O Processo de Criação no Design Conceitual. Explorando o potencial reflexivo e dialético do projeto. Tessituras \& Criação. São Paulo, v. 1, n. 1, 2011. Disponível em:

<https://revistas.pucsp.br/index.php/tessituras/article/view/5612> Acesso em 1 abr. 2018.

Carlo. A Forma Das Ideias. Concept Design E Design Conceitual Ideas Form. Concept

Design And Conceptual Design. In: CONGRESSO INTERNACIONAL DA ASSOCIAÇÃO DE PESQUISADORES EM CRÍTICA GENÉTICA, 10., 2012.

KRIPPENDORFF, Klaus. Design centrado no ser humano: uma necessidade cultural. In: Estudos em Design. v.8, n.3 (maio), 2000. Rio de Janeiro:Associação de Ensino de Design do Brasil. p. 87-98.

LACLAU, E.; MOUFFE, C. Hegemonia y estrategia socialista: hacia una radicalización da la democracia. 2a. ed. Buenos Aires: Fondo de Cultura Económica, 2004.

LATOUR, Bruno. Um Prometeu cauteloso?: alguns passos rumo a uma filosofia do design (com especial atenção a Peter Slotedijk). Agitprop: revista brasileira de design, São Paulo, v. 6, n. 58, jul./ago. 2014.

NECYK, B. FERREIRA; P. Educação para o design. 9o Congresso Brasileiro de Pesquisa e Desenvolvimento em Design. São Paulo. 2010.

SOUZA LEITE, João de. O discurso do design gráfico como polifonia. ECO/UFRJ. 1996. 